\title{
World Regionalization of Climate Change (1961-2010)
}

\author{
Peijun Shi ${ }^{1,2,3} \cdot$ Shao Sun ${ }^{1,2,3} \cdot$ Daoyi Gong ${ }^{1,3} \cdot$ Tao Zhou ${ }^{1,3}$
}

Published online: 13 September 2016

(c) The Author(s) 2016. This article is published with open access at Springerlink.com

\begin{abstract}
Traditional climate classification or regionalization characterizes the mean state of climate condition, which cannot meet the demand of addressing climate change currently. We have developed a climate change classification method, as well as the fundamental principles, an indicator system, and mapping techniques of climate change regionalization. This study used annual mean temperature and total precipitation as climatic indices, and linear trend and variation change as change indices to characterize climate change quantitatively. The study has proposed a scheme for world climate change regionalization based on a half century of climate data (1961-2010). Level-I regionalization divides the world into 12 tendency zones based on the linear trend of climate, level-II regionalization resulted in 28 fluctuation regions based on the variation change of climate. Climate change regionalization provides a scientific basis for countries and regions to develop plans for adapting to climate change, especially for managing climate-related disaster or environmental risks.
\end{abstract}

Keywords Climate change - Regionalization . Temperature $\cdot$ Precipitation · Tendency ·

Fluctuation · World

Peijun Shi

spj@bnu.edu.cn

1 State Key Laboratory of Earth Surface Processes and Resource Ecology, Beijing Normal University, Beijing 100875, China

2 Key Laboratory of Environmental Change and Natural Disasters of Ministry of Education, Beijing Normal University, Beijing 100875, China

3 Academy of Disaster Reduction and Emergency Management, Ministry of Civil Affairs \& Ministry of Education, Beijing 100875, China

\section{Introduction}

Climate condition is the foundation for the sustainable development of human society. Since the Industrial Revolution 200 years ago, many of the observed climate changes are unprecedented over millennia, and have begun to influence the natural environment seriously IPCC 2012, 2013). Addressing climate change has become a global issue that has attracted the attention of politicians, scientists, and the public worldwide. We believe that climate change adaptation should be in line with regional and local conditions, that is, based on an analysis of the relationship between different climate change types and related disasters or environmental risks.

Traditional climate classifications and regionalization schemes characterize the mean state of climate condition (Köppen 1936; Thornthwaite 1948; Strahler 1975) for which the indices are the mean value of climate variables over a certain period of time. With climate change accelerating nowadays, these traditional works cannot meet the demand of climate change adaptation. In the past century, global warming was the main feature of climate change; however, the rate of temperature increase varied greatly from high latitudes to equatorial areas, while temperature was even cooling in the Andes Mountains of South America. Other climatic indices including precipitation, potential evapotranspiration, wind speed, and so on also showed regional differentiation patterns on different temporal scales, and the features were more complicated (Dai et al. 1997; Emori and Brown 2005; Hansen et al. 2010; Wu et al. 2011; Ji et al. 2014).

We had developed a set of classification methods that identify regional differences of climate change, and had used these methods to complete the climate change regionalization in China (Shi et al. 2014). This study used 
the same methods and global gridded datasets of temperature and precipitation from 1961 to 2010 to recognize climate change quantitatively, and puts forward a scheme of climate change regionalization on a world scale with administrative subdivisions of countries and regions as the basic unit.

\section{Data and Methods}

Data used in the research mainly include meteorological data, topographic data, and administrative boundary data. Change in climatic variables was divided into linear trend and variation change, that is, tendency and fluctuation. This article uses annual mean temperature and annual precipitation as the two most important climatic variables with which to diagnose climate change. The confidence of linear regression is calculated by the F-test method during the calculation of indices to evaluate the reliability of the results.

\subsection{Data Sources}

Temperature data are derived from the Monthly Dataset $\left(0.5^{\circ}\right.$ resolution, from January 1961 to December 2010) of the Climatic Research Unit, University of East Anglia (Mitchell and Jones 2005), precipitation data are from the Monthly Dataset $\left(0.5^{\circ}\right.$ resolution, from January 1961 to December 2010) of Global Precipitation Climatology Centre $^{1}$ (Schneider et al. 2011). Topographic data are from Global 30 Arc-Second Elevation dataset provided by the United States Geological Survey. ${ }^{2}$ Administrative boundary data are from Global Administration database, developed by Robert Hijmans, University of California, Davis. ${ }^{3}$

\subsection{Calculation Methods}

Climate change can be classified into nine modes based on tendency (rise, decline, not significant) and fluctuation (increase, decrease, not significant) of the climatic variables (Shi et al. 2014), as shown in Fig. 1.

For the original series $x_{i}$, considering the disturbance of interannual scale variation, first apply the moving average method to establish a 5-year moving average series $y_{i} ; t_{i}$ represents the corresponding time. Then develop a linear regression equation between $y_{i}$ and $t_{i}$ :

\footnotetext{
${ }^{1}$ https://climatedataguide.ucar.edu/climate-data/gpcc-global-precipi tation-climatology-centre.

2 https://lta.cr.usgs.gov/GTOPO30.

${ }^{3}$ http://www.gadm.org/.
}

$\hat{y}_{i}=a+b t_{i}$.

The regression coefficient $b$ is called the "tendency value," which can be calculated through the least square method. Tendency value represents the linear trend of variables, that is, the rate of increase or decline.

The absolute residuals series $f_{i}$ of $y_{i}$ and the linear fitting series is:

$f_{i}=\left|y_{i}-a-b t_{i}\right|$.

The $\bar{f}_{i}$ of the absolute residuals series $f_{i}$ is called the mean fluctuation value.

For the absolute residuals series $f_{i}, t_{i}$ represents the corresponding time, a linear regression equation between $f_{i}$ and $t_{i}$ is as follows:

$\hat{f}_{i}=c+d t_{i}$.

Similarly, the regression coefficient $d$ is called the "fluctuation value," which represents the linear trend of absolute residuals series, that is, the rate of increase or decrease of fluctuation.

\subsection{Confidence Test}

The result of a confidence test is classified by different indices and confidence standards, shown in Table 1. In the table, "Not significant" means there is no significant tendency or fluctuation under certain confidence.

For level-I indices, $97 \%$ grids are significant with respect to temperature tendency under $90 \%$ confidence, while $57 \%$ grids are significant with respect to precipitation tendency. For level-II indices, grids with significant fluctuation of temperature or precipitation are lower than that of tendency; under $90 \%$ confidence, $38 \%$ grids are significant in respect of temperature fluctuation, while $49 \%$ grids are significant in terms of precipitation fluctuation.

\section{Spatial Distribution of Climate Change (1961-2010)}

The spatial distribution of temperature and precipitation tendency values is shown in Fig. 2. Temperature tendency shows latitudinal zonality at the world scale and the rising rate is higher in the northern high latitudes than the northern low latitudes and southern hemisphere, while some areas show cooling in the past 50 years on a regional scale, such as the Andes Mountains and northwest Australia. The regional features of precipitation tendency are more complex than those of temperature tendency. The wet trend areas mainly include Europe, Asia, Oceania, North America and Western South America, while the dry trend 


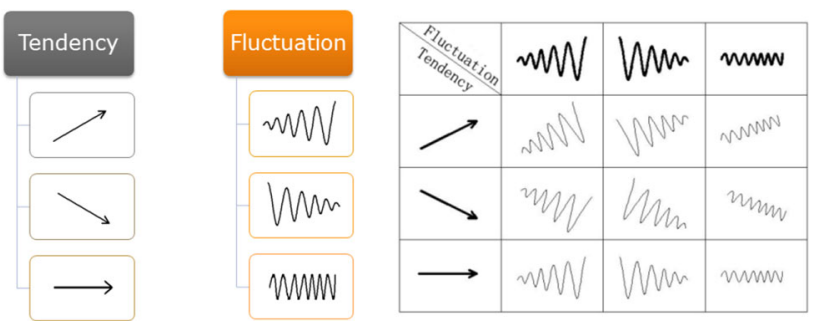

Fig. 1 Modes of climate change

Table 1 Classified statistics of grids under different confidence standard $(\%)$

\begin{tabular}{lllll}
\hline \begin{tabular}{l} 
Classification of $\begin{array}{l}l \\
\text { index }\end{array}$ \\
\cline { 2 - 4 }
\end{tabular} & $0-100 \%$ & $66-100 \%$ & $90-100 \%$ & $99-100 \%$ \\
& & (Likely) & $\begin{array}{c}\text { Cery } \\
\text { likely) }\end{array}$ & $\begin{array}{c}\text { (Virtually } \\
\text { certain) }\end{array}$ \\
\hline
\end{tabular}

Level-I indices

Temperature tendency

$\begin{array}{lr}\text { Rise } & 97 \\ \text { Decline } & 3\end{array}$

Not significant

96

2

Precipitation tendency

Rise $\quad 56$

Decline 44

Not significant

Level-II indices

Temperature fluctuation

\begin{tabular}{lcccr} 
Increase & 46 & 26 & 15 & 6 \\
Decrease & 54 & 34 & 23 & 12 \\
Not significant & & 40 & 62 & 82 \\
Precipitation fluctuation & & & \\
Increase & 59 & 44 & 34 & 24 \\
Decrease & 41 & 25 & 15 & 6 \\
Not significant & & 31 & 51 & 70 \\
\hline
\end{tabular}

areas are mainly concentrated in tropical Africa, West Asia, and eastern South America on a continent scale.

The spatial distribution of temperature and precipitation fluctuation values is shown in Fig. 3. The areas in which temperature fluctuation is increasing mainly include Western Europe, central Africa, East Asia, Australia, and northern North America, while the areas with decreasing temperature fluctuation mainly cover western and southern Africa, North Asia, Central Asia, southern North America, and South America when examined at the continental scale. For precipitation fluctuation, the increasing areas mainly include Asia and North America, while decreasing areas mainly cover Europe, Africa, West Asia, Australia, and South America.

\section{World Regionalization of Climate Change (1961-2010)}

Based on the regional differentiation patterns of climate change (Sect. 3), we further propose a fundamental method of climate change regionalization that includes a set of basic principles, an indicator system, and a regionalization method. This scheme of climate change regionalization is designed using datasets assembled from the five decades between 1961 and 2010 .

\subsection{Principles, Indicators, and Method}

Five basic principles considered in our regionalization method include:

(1) keep intact the boundaries of major administrative subdivisions of countries (the state boundaries of the US, for instance);

(2) consider only leading climate factors (temperature and precipitation);

(3) preserve spatial distribution continuity (the essential difference between climate classification and regionalization);

(4) combine key indices with auxiliary indices (direction of change as key indices, rate of change as auxiliary indices); and

(5) retain the consistency of large-scale terrain units that are important to land-atmosphere interaction.

The regionalization that results from these principles is divided into two levels: climate tendency zones (level-I) and climate fluctuation regions (level-II). For level-I regionalization, we take temperature tendency as the main indicator by which to divide the world into warming-trend zones and cooling-trend zones, while the rate of change is regarded as the auxiliary indicator for determining regionalization boundaries. Precipitation tendency is divided in the same way. In addition, considering that $97 \%$ of the land area showed a warming trend, we further adopted the average rate of temperature rise $\left(0.22{ }^{\circ} \mathrm{C} / 10\right.$ a between 1961 and 2010) as the threshold value with which to divide the world into a rapidly rising temperature zone and a slowly rising zone. Specifically, $0.22{ }^{\circ} \mathrm{C} / 10$ a is the mean of the temperature tendency values of all the grids located in the global land area except Antarctica (see Fig. 2a).

For level-II regionalization, we take temperature fluctuation as the main indicator that divides the world into temperature fluctuation increasing regions and temperature fluctuation decreasing regions, with the rate of change as the auxiliary indicator for determining regionalization boundary. Precipitation fluctuation is divided in the same way. 

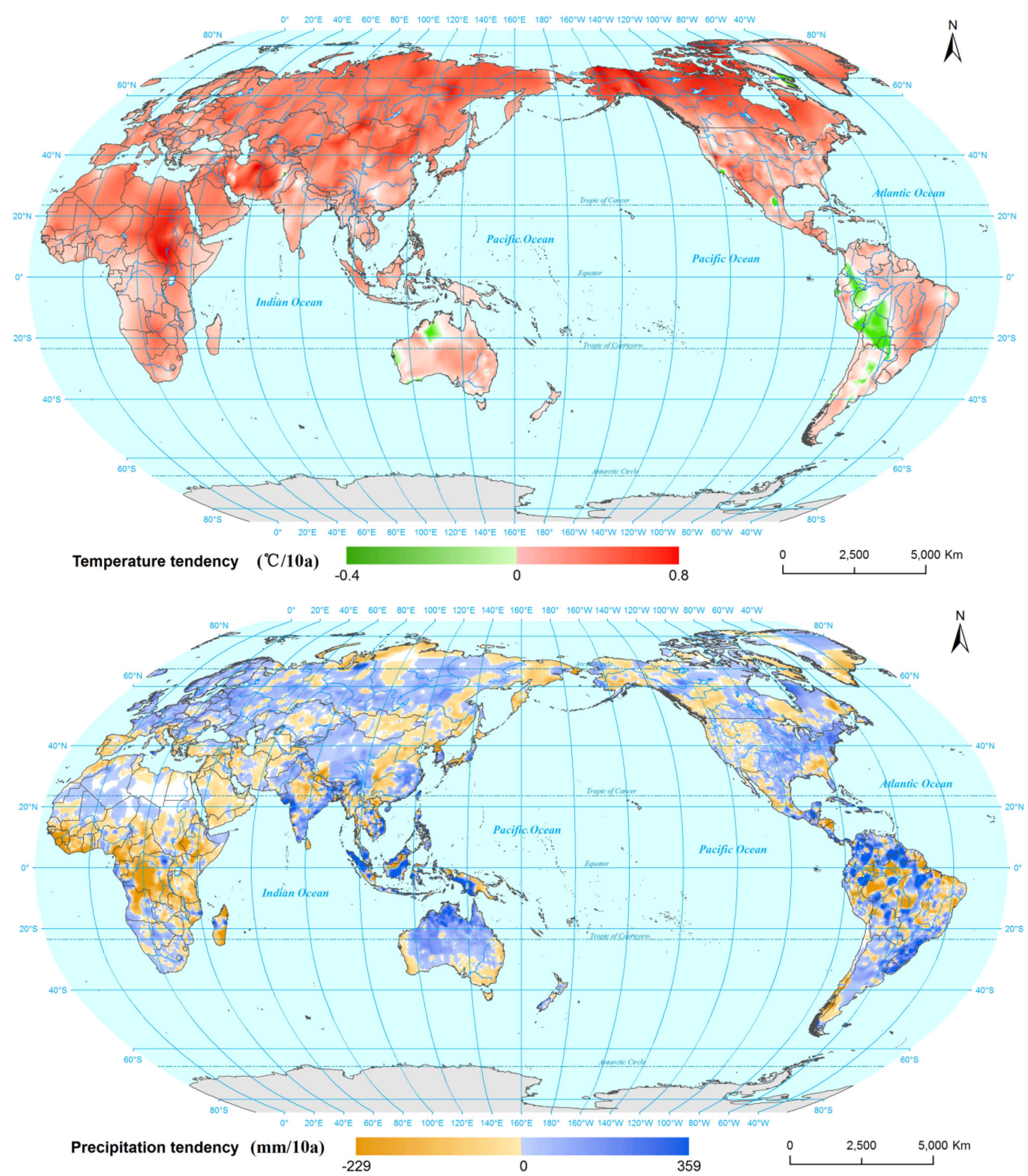

Fig. 2 Spatial distribution of temperature and precipitation tendency values. a Temperature tendency from 1961 to 2010 , and b precipitation tendency from 1961 to 2010

The mapping work is implemented in ArcGIS environment, in which the zonal statistics, dissolve, and superimposed tools are adopted. For level-I zones, first apply the zonal statistics tool to calculate the mean value of grids of each unit (administrative subdivisions of countries). Then classify each unit into different types according to the direction of change. Third, use the dissolve tool to combine the units of same type, obtain the zoning result of level-I 

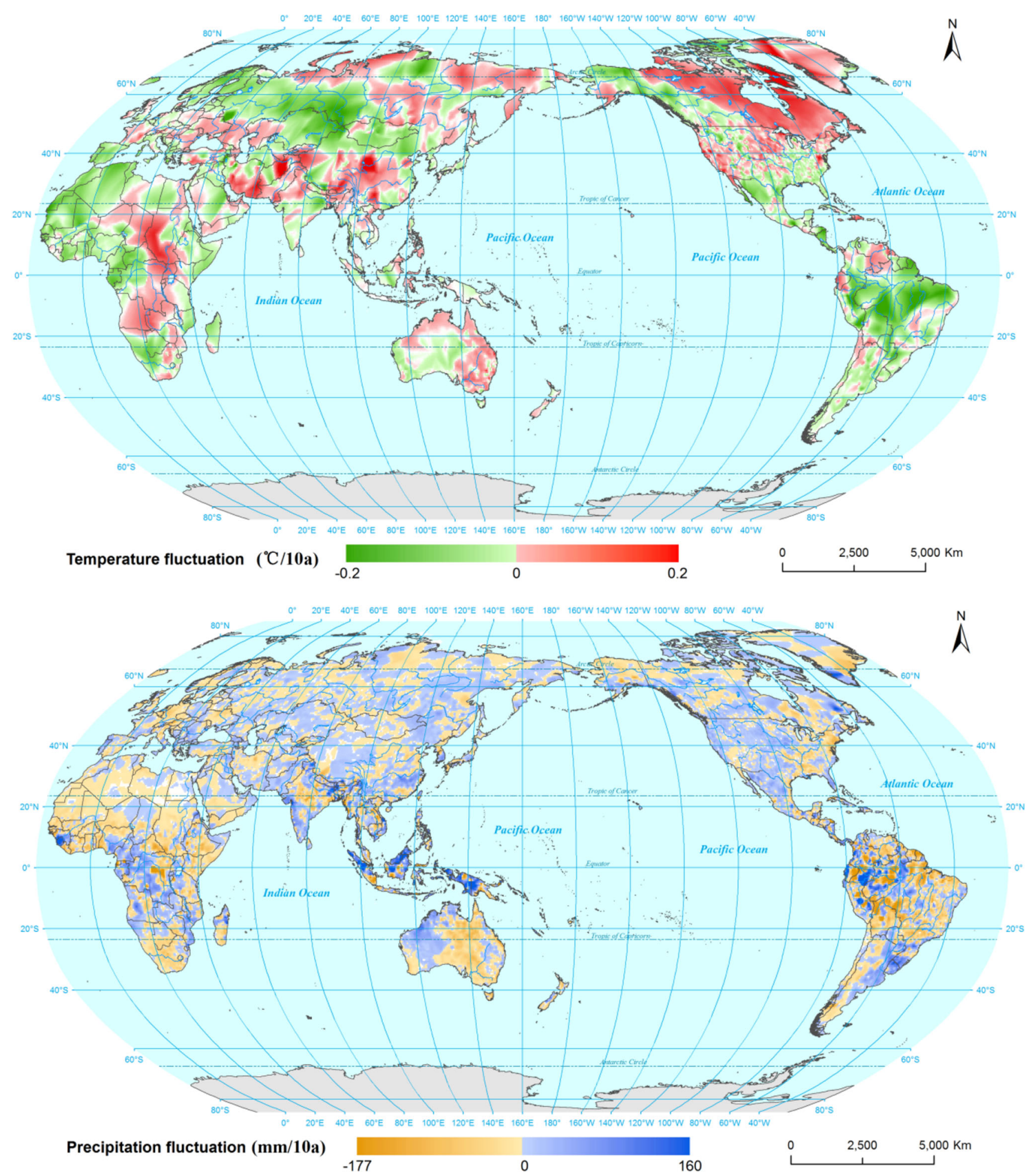

Fig. 3 Spatial distribution of temperature and precipitation fluctuation values. a Temperature fluctuation from 1961 to 2010 , and $\mathbf{b}$ precipitation fluctuation from 1961 to 2010

regionalization. Level-II regionalization is processed with the same method. Finally, apply the superimposed tool to overlay the zoning results of level-I and level-II regionalization and complete the zoning map.

\subsection{Result}

Temperature and precipitation tendency values (Fig. 2) are adopted to divide the world into six tendency types. The 


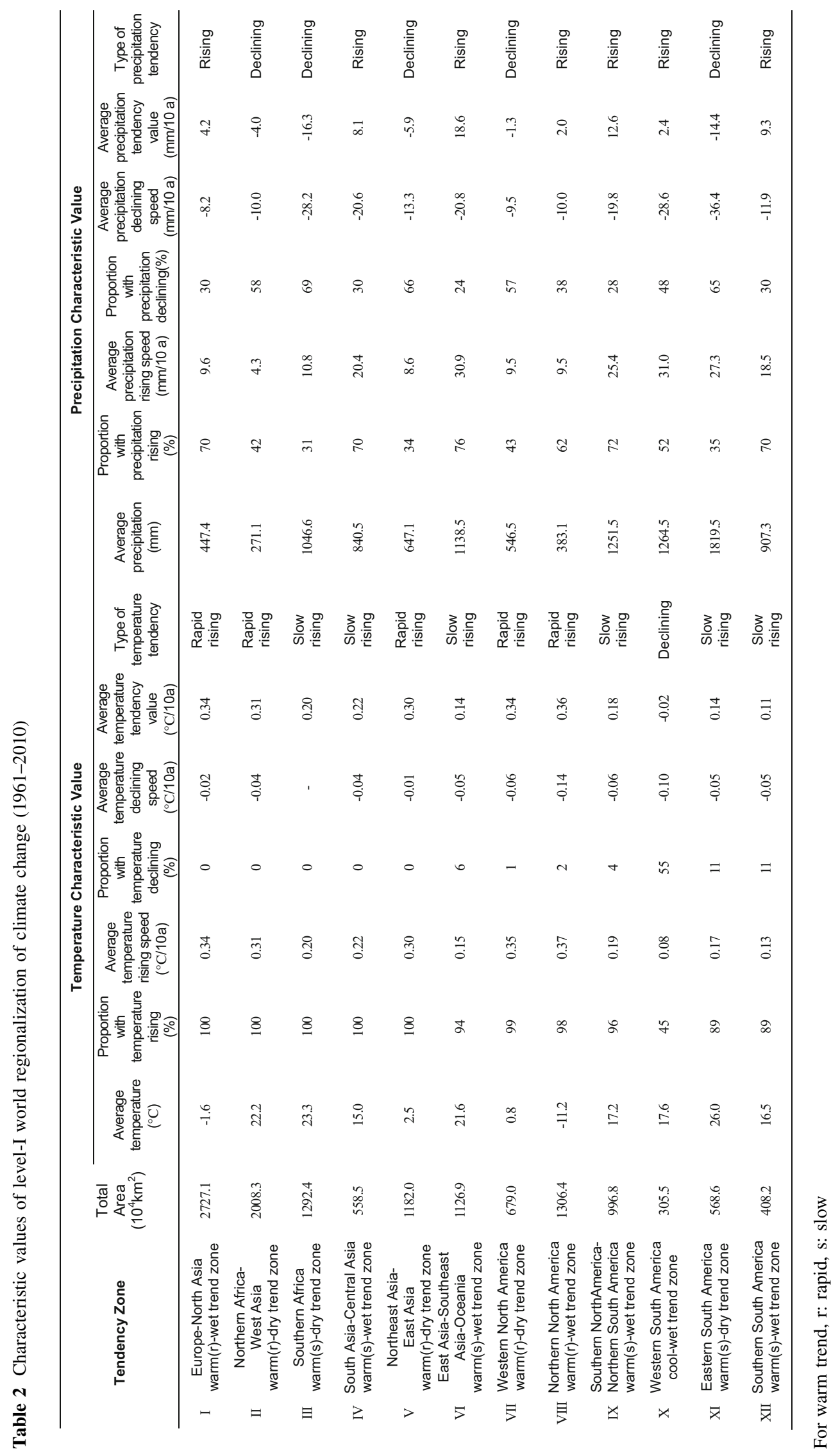




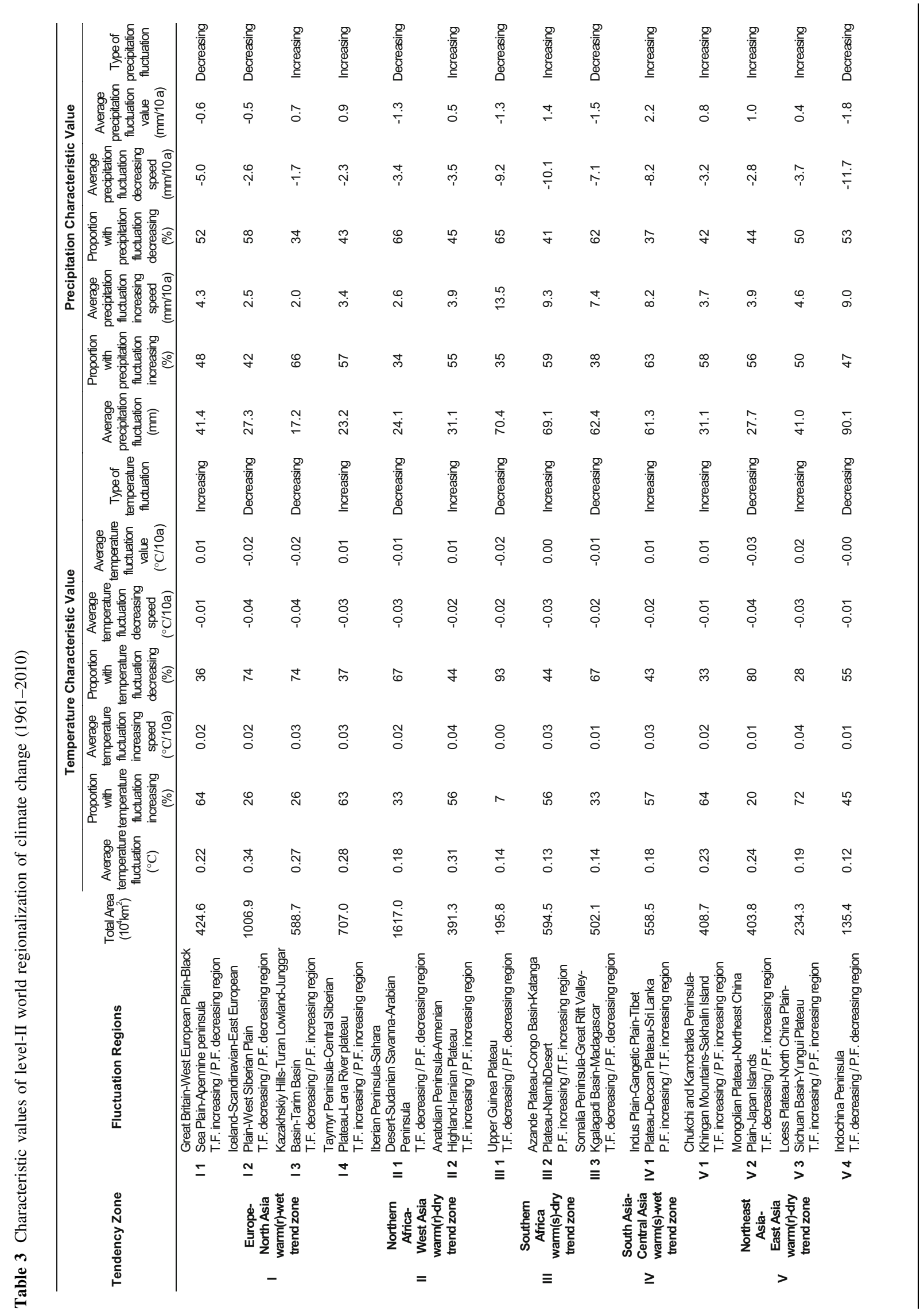




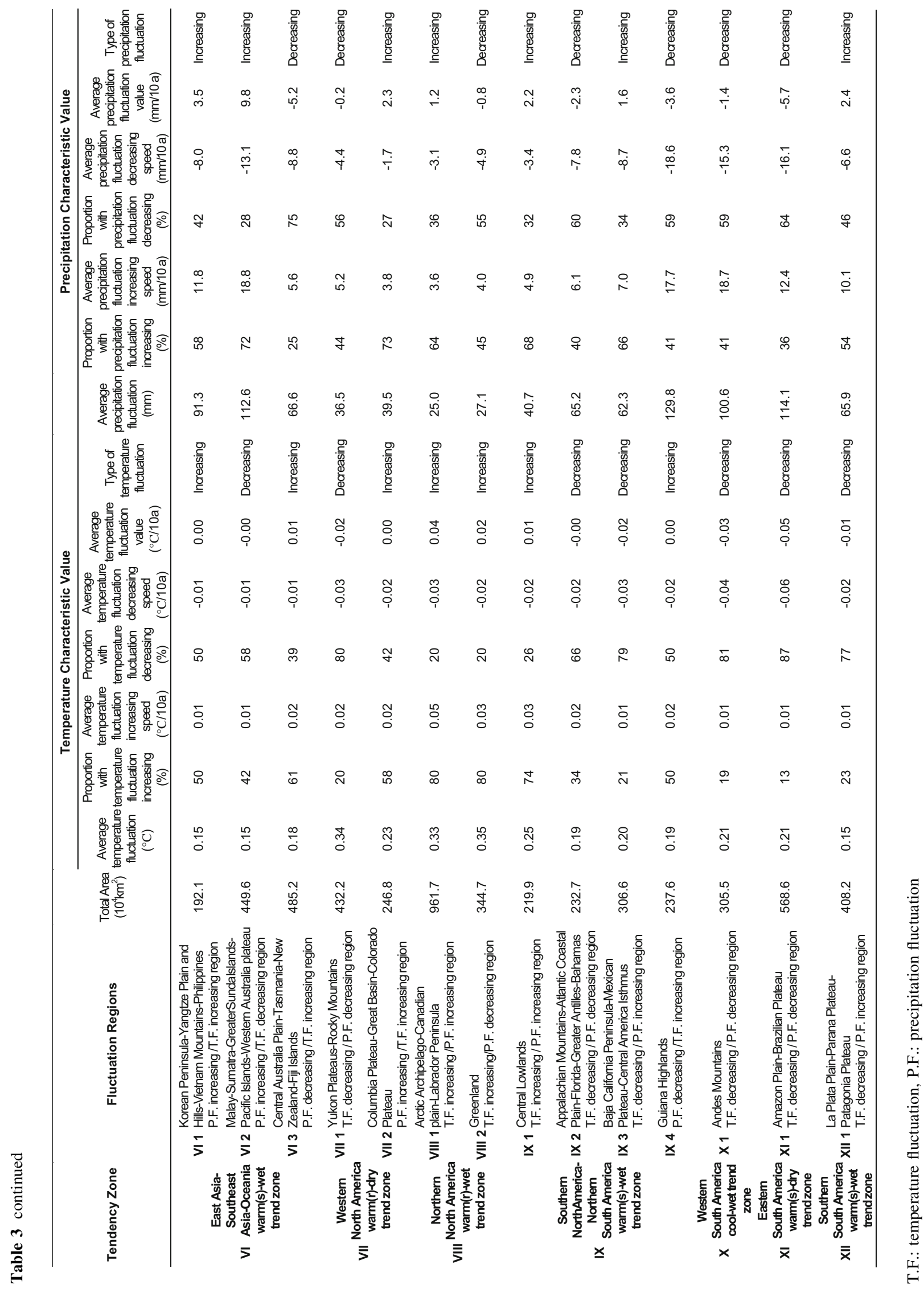



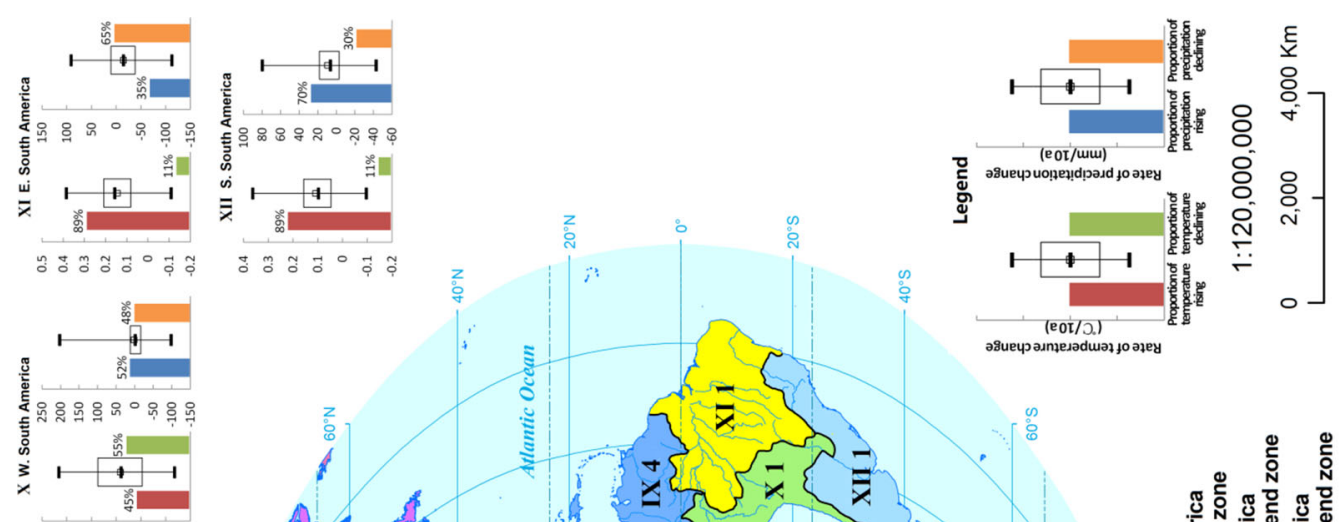

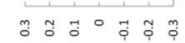

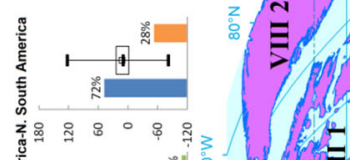

는

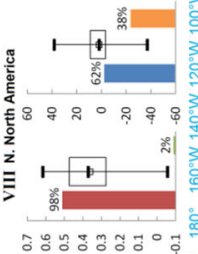
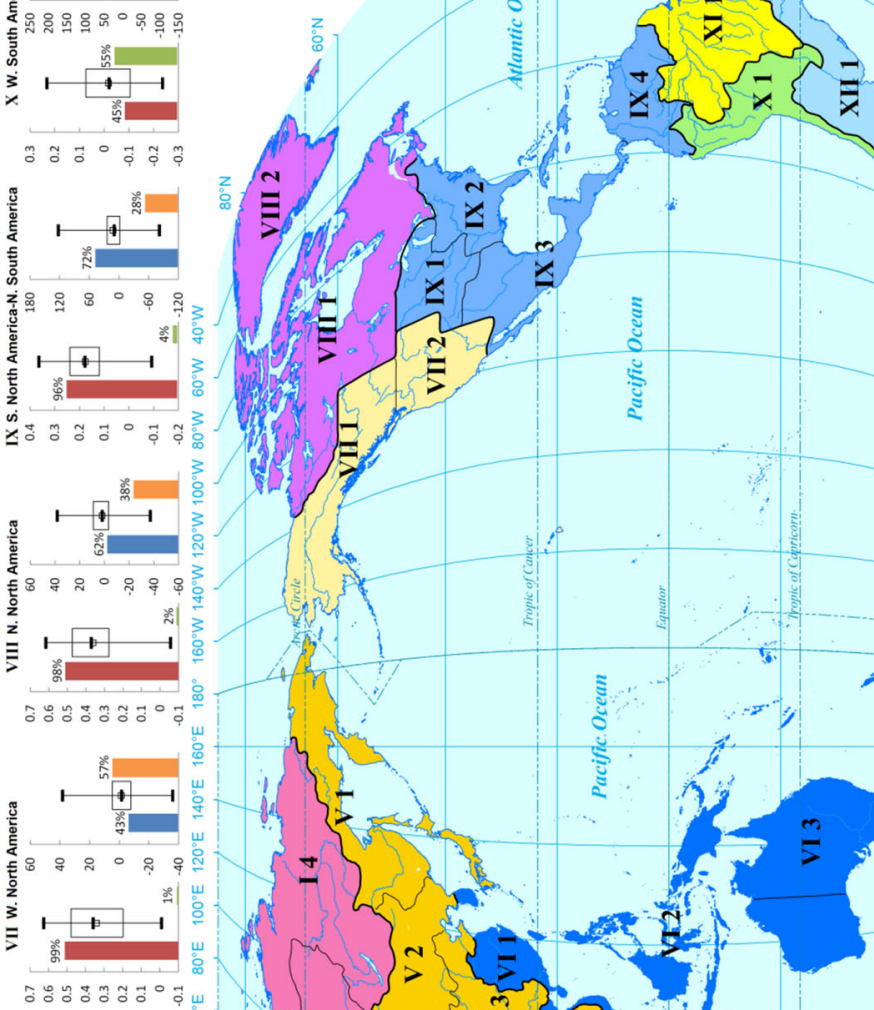

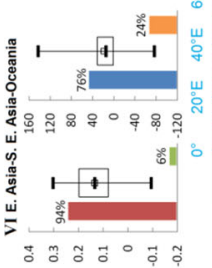
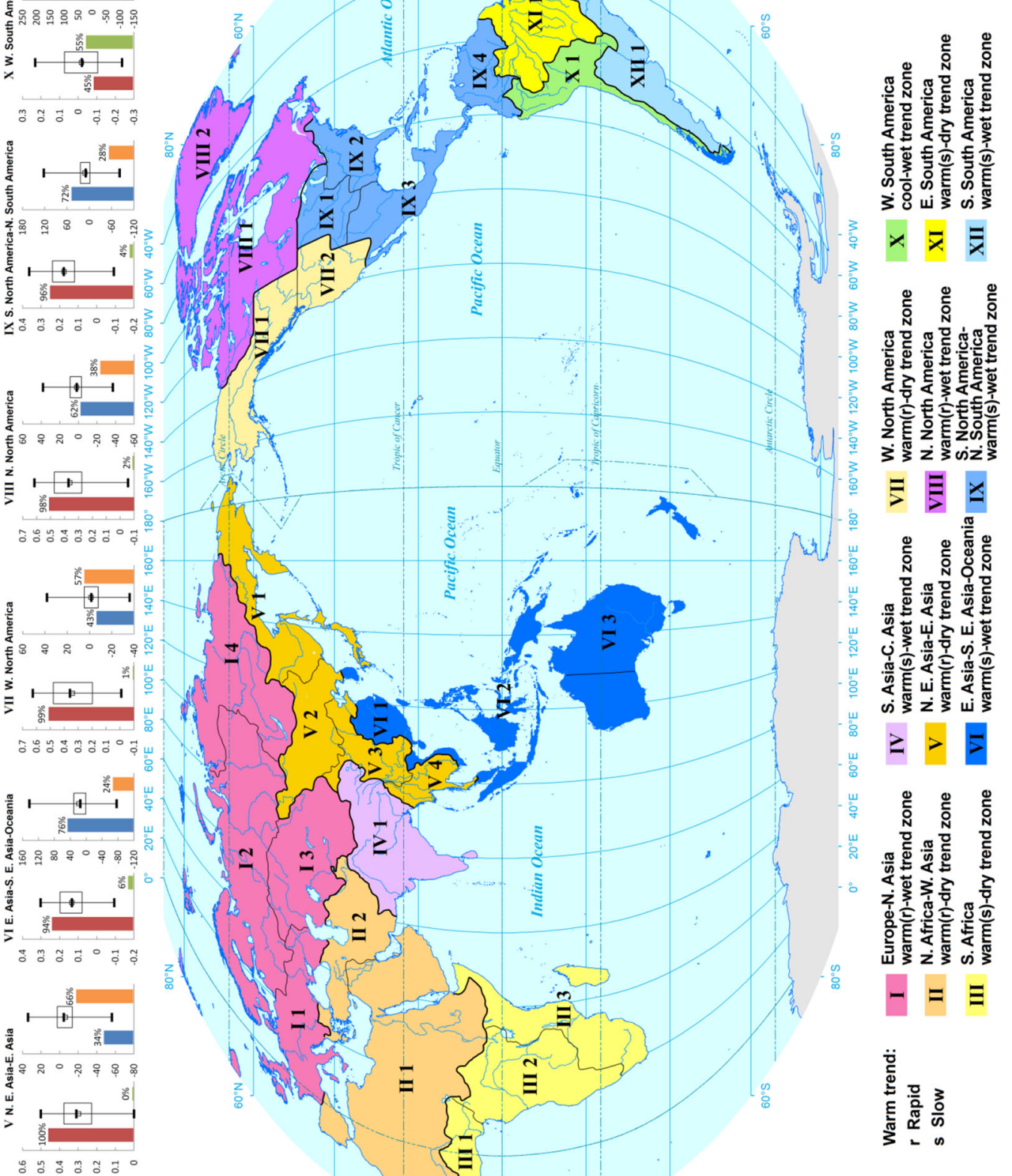

三目凶

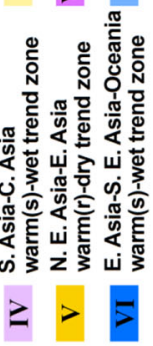

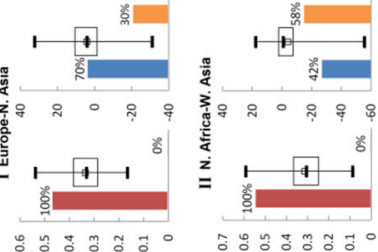

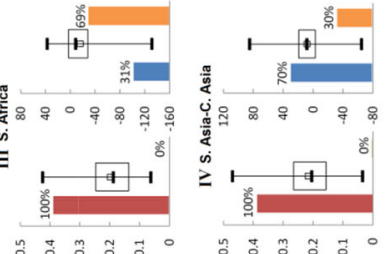


warm(rapid)-wet type accounts for $36.8 \%$ of the global land area, and the warm(rapid)-dry type accounts for $27.6 \%$, the warm(slow)-wet type accounts for $17.6 \%$, the warm(slow)-dry type accounts for $15.1 \%$, the cool-wet type accounts for $1.4 \%$, and the cool-dry type accounts for $1.5 \%$ of the global land area, respectively.

Level-I regionalization resulted in 12 tendency zones, that is, Europe-North Asia warm(rapid)-wet trend zone, Northern Africa-West Asia warm(rapid)-dry trend zone, Southern Africa warm(slow)-dry trend zone, South AsiaCentral Asia warm(slow)-wet trend zone, Northeast AsiaEast Asia warm(rapid)-dry trend zone, East Asia-Southeast Asia-Oceania warm(slow)-wet trend zone, Western North America warm(rapid)-dry trend zone, Northern North America warm(rapid)-wet trend zone, Southern North America-Northern South America warm(slow)-wet trend zone, Western South America cool-wet trend zone, Eastern South America warm(slow)-dry trend zone, and Southern South America warm(slow)-wet trend zone. Characteristic values of all climate tendency zones according to classified indicators are shown in Table 2.

Temperature and precipitation fluctuation values (Fig. 3) are adopted to divide the world into four fluctuation types. The temperature and precipitation fluctuation increasing type accounts for $18.7 \%$, the temperature fluctuation increasing and precipitation fluctuation decreasing type accounts for $39.9 \%$, the temperature fluctuation decreasing and precipitation fluctuation increasing type accounts for $19.5 \%$, and the temperature and precipitation fluctuation decreasing type accounts for $21.9 \%$ of the global land area, respectively.

The level-II regionalization divides the world into 28 fluctuation regions, based on level-I regionalization. Characteristic values of all climate fluctuation regions according to classified indicators are shown in Table 3 . Combine level-I regionalization and level-II regionalization, then name them by geomorphic features, the world regionalization of climate change (1961-2010), as shown in Fig. 4, is completed.

\section{Discussion}

In addition to the calculation reported in this article, we have also applied an ensemble empirical mode decomposition method and Bayesian approach to analyze the regional differences of climate indicators, and the patterns are approximately the same. However, it is worth mentioning that there are different understandings concerning the variation change. Considering the study period of the last half-century, in this article we focused on interdecadal changes. In the future, we will try to diagnose climate change on interannual, seasonal, and monthly scales, which should be conducive to analysis of the relationship between climate change and environmental risks.

There are essential differences between climate change regionalization and traditional climate regionalization. The result of climate change regionalization depends on the spatial and temporal scales selected, that is, climate change regionalization shows certain differences at various scales. Next step, we shall carry out research also at different spatial scales to further reveal the variation range of climate change patterns.

Considering that existing disaster databases of the world mainly use countries or regions as the basic spatial unit and lack spatial specificity, this study selected administrative subdivisions of countries as the basic unit of the regionalization. Our research aimed to probe an important impacting factor in disaster risks and to reveal the driving forces of climate-related disasters and environmental risk of countries in the world through understanding the regional differences of climate change.

\section{Conclusion}

This article is an outgrowth of earlier work (Shi et al. 2014), which explores the pace and direction of climate change in China over the last half century. Our primary goal was to develop a methodology and model that could generate a map that accurately reflect a scientifically defensible understanding of regional variation in climate change. In the current article, we have extended this model to a global scale and have demonstrated that it is technically possible to create a spatially nuanced approximation of climate change. With five decades of data at our disposal, it is possible to separate variation from trend and identify subnational areas impacted by climate change. In this sense, our work contributes a technical platform to the study of regional climate change. Our method potentially can be used to explore the scale, direction, and pace of climate change in a variety of spatial and temporal contexts. The model also offers the prospect of positive employment in disaster risk management and planning. By identifying regions most threatened by rapid, climate change-induced instability, disasters may be better mitigated and risks reduced.

Open Access This article is distributed under the terms of the Creative Commons Attribution 4.0 International License (http://creative commons.org/licenses/by/4.0/), which permits unrestricted use, distribution, and reproduction in any medium, provided you give appropriate credit to the original author(s) and the source, provide a link to the Creative Commons license, and indicate if changes were made. 


\section{References}

Dai, A., I.Y. Fung, and A.D. Del Genio. 1997. Surface observed global land precipitation variation during 1900-88. Journal of Climate 10: 2943-2962.

Emori, S., and S.J. Brown. 2005. Dynamic and thermodynamic changes in mean and extreme precipitation under changed climate. Geophysical Research Letters 32(17): L17706. doi:10. 1029/2005GL023272.

Hansen, J., R. Ruedy, M. Sato, and K. Lo. 2010. Global surface temperature change. Reviews of Geophysics 48(4): RG4004. doi:10.1029/2010RG000345.

IPCC (Intergovernmental Panel on Climate Change). 2012. IPCC special report on managing the risks of extreme events and disasters to advance climate change adaptation (SREX). Cambridge: Cambridge University Press.

IPCC (Intergovernmental Panel on Climate Change). 2013. IPCC climate change 2013: The physical science basis. Cambridge: Cambridge University Press.

Ji, F., Z.H. Wu, J.P. Huang, and E.P. Chassignet. 2014. Evolution of land surface air temperature trend. Nature Climate Change 4: $462-466$.
Köppen, W.P. 1936. The geographical system of climates (Das geographische system der klimate). In Handbook of climatology (Handbuch der klimatologie), ed. W.P. Köppen, and R. Geiger, 1-44. Berlin: Gebrüder Borntraeger.

Mitchell, T.D., and P.D. Jones. 2005. An improved method of constructing a database of monthly climate observations and associated high-resolution grids. International Journal of Climatology 25(6): 693-712.

Schneider, U., A. Becker, P. Finger, A. Meyer-Christoffer, B. Rudolf, and M. Ziese. 2011. GPCC full data reanalysis version 6.0 at 0.5 : Monthly land-surface precipitation from rain-gauges built on GTS-based and historic data. doi:10.5676/DWD_GPCC.

Shi, P.J., S. Sun, M. Wang, N. Li, J.A. Wang, Y.Y. Jin, X.T. Gu, and W.X. Yin. 2014. Climate change regionalization in China (1961-2010). Science China Earth Sciences 57(11): 2690-2701.

Strahler, A.N. 1975. Classification of global climates. In Physical geography, ed. A.N. Strahler, 243-245. New York: John Wiley.

Thornthwaite, C.W. 1948. An approach toward a rational classification of climate. Geographical Review 38(1): 55-94.

Wu, Z.H., N.E. Huang, J.M. Wallace, B.V. Smoliak, and X.Y. Chen. 2011. On the time-varying trend in global-mean surface temperature. Climate Dynamics 37: 759-773. 